\title{
ANALISIS KEMAMPUAN TEKNIK CONTROL, HEADING DAN PASSING SISWA EKSTRAKURIKULER FUTSAL SMP NEGERI 13 KOTA BENGKULU
}

\section{Samuel Surantha Ginting}

PENJAS FKIP UNIB, e-mail: surantasamuel@gmail.com

\author{
Syafrial \\ Universitas Bengkulu \\ Defliyanto
}

Universitas Bengkulu

\begin{abstract}
Abstrak
Permainan futsal harus memiliki teknik dasar yang mumpuni, seperti mengoper (passing), menerima (control), menggiring (dribbling), menendang (shooting), dan menyundul (heading). Tujuan penelitian ini adalah untuk mengetahui kemampuan teknik control, heading dan passing siswa ekstrakulikuler futsal SMP N 13 Kota Bengkulu, yang berkenaan dengan latihan tambahan ekstrakulikuler futsal, mengetahui hasil analisis teknik control, heading dan passing menjadi tolak ukur pelatih dan siswa untuk lebih meningkatkan kemampuan teknik dalam permainan futsal. Metode yang digunakan adalah metode penelitian deskriptif kuantitatif yang menggambarkan situasi atau keadaan yang sedang berlangsung dengan melakukan tes. Instrumen dari penelitian ini yaitu Observasi, Wawancara, Tes dan Dokumentasi. Hasil penelitian menunjukkan bahwa dengan meningkatnya teknik-teknik siswa maka siswa lebih dapat memaksimalkan bola-bola di lapangan baik dalam bertahan maupun menyerang dan akan memberikan pengaruh yang efektif dalam menjuarai kompetisi. Berdasarkan Analisis Kemampuan Teknik Control, Heading dan Passing Siswa Ekstrakurikuler Futsal SMP Negeri 13 Kota Bengkulu, rata-rata keseluruhan control, heading dan passing dengan jumlah control sebanyak 3099 kali (46\%), heading rata-rata skor 6,5, dan passing sebanyak 2673 kali (56\%).
\end{abstract}

Kata kunci : Teknik Control, Teknik Heading, Teknik Passing, Pola Permainan

\begin{abstract}
Futsal players should have the basic techniques are qualified, such as passes, control, dribbling, shooting, heading. The purpose of this research is to determine the students ability of control, heading and passing technique on futsal extracurricular of SMP N 13 Bengkulu, analysis the control, heading and passing techniques; and put its become the trainers or student reference to further improve the students techniques. The research method is a Quantitative Descriptive that describes the a situation or ongoing situation by conducting the examination. Instruments of this research are: Observation, Interview, Examination and Documentation. The results of this research obviously showed that the better of skill ability of student will maximize balls both in defense or strike out and given more chance for winning every competition. Based on Control, Heading and Passing Technique Capability Analysis of Futsal Extracurricular of SMP N 13 Bengkulu; Average
\end{abstract}


overall control, heading and passing with the number of controls as many 3099 times (46\%), average heading score of 6,5 and passing 2673 times (56\%).

Keywords: Technical Control, Technical Heading Technical Passing, Game Pattern.

\section{PENDAHULUAN}

Futsal merupakan olahraga menarik dan dinamis, hal ini di karenakan ukuran lapangan yang kecil, selama permainan futsal berlangsung bola selalu bergulir cepat dari kaki ke kaki. Futsal adalah suatu jenis olahraga yang menuntut pemain mempunyai teknik tinggi. Tipe permainan yang menjadi ciri khas olahraga futsal adalah adanya situasi yang berubah secara cepat. Setiap situasi posisi hanya berlangsung hitungan detik sebelum berganti dengan situasi berikutnya. Karena itu dibutuhkan kemampuan yang tinggi dan benar dalam waktu singkat dari para pemainnya.

Setiap pemain pasti ingin mempunyai prestasi yang tinggi dalam bermain futsal, karena itu dalam meningkatkan prestasi permainan futsal, pemain perlu meningkatkan kemampuan teknik dalam bermain. Adapun faktorfaktor yang mempengaruhi kemampuan teknik dalam olahraga futsal yaitu : mengoper (passing), mengontrol (controlling), menggiring (dribbling), menyundul (heading), dan menembak (shooting). Teknik dalam olahraga futsal saling berkaitan untuk menciptakan permainan yang bagus, kesalahan yang dominan terdapat pada ketepatan dalam menyundul bola (heading).

$$
\text { Heading adalah cara untuk }
$$
menguasai bola, mengumpan kepada rekan setim dan untuk mencetak gol dengan menggunakan kepala, Muhammad Asriady Mulyono (2014 : 61). Heading sering dilakukan pemain saat bola berada diudara, tetapi heading dapat juga dilakukan saat bola berada di bawah (drive heading). Teknik heading memerlukan latihan rutin karena tidak mudah melakukannya. Pemain harus menjaga keseimbangan, ketepatan waktu, dan kecermatan dalam membaca arah sehingga bola bisa disundul dengan baik dan sempurna.

Peningkatan kemampuan teknik dalam olahraga futsal sangat di perlukan agar terciptanya prestasi yang baik, terutama dalam teknik heading, siswa tidak dapat mengontrol dengan kepala, sehingga dalam bertahan dan melakukan penyerangan terhadap lawan lewat udara tidak dapat dimaksimalkan oleh para pemain. Adanya pembinaan yang baik terhadap ekstrakulikuler futsal SMP N 13 Kota Bengkulu dapat memiliki kualitas teknik, skill dan menjadikan tim futsal SMP N 13 Kota Bengkulu dapat bersaing juara dengan SMP Negeri yang ada di Kota Bengkulu. Adanya pembinaan yang baik, kualitas tim yang sama rata menjadikan olahraga futsal di tingkat SMP Negeri Kota Bengkulu semakin banyak diminati dan berkembang.

Berdasarkan uraian pada latar belakang masalah dan batasan masalah diatas, maka dapat dirumuskan permasalahan penelitian sebagai berikut : "Bagaimanakah kemampuan teknik heading dalam latihan pada ekstrakulikuler futsal SMP N 13 Kota Bengkulu dengan arah, dan ketepatan kepala terhadap bola?"

\section{KAJIAN TEORI}

Menahan bola (control) dalam permainan futsal harusmenggunakan telapak kaki, karena dengan permukaan lapangan yang rata maka bola akan bergulir cepat sehingga para pemain harus dapat mengontrol bola dengan baik, apabila menahan bola jauh dari kaki maka 
lawan akan mudah merebut bola yang kita kuasai. Yang harus dilakukan pada saat menahan bola yaitu : Selalu melihat datangnya bola, jaga keseimbangan badan pada saat datangnya bola, dan sentuh atau tahan bola dengan menggunakan telapak kaki agar bolanya diam tidak bergerak dan mudah dikuasai. Menyundul (heading) merupakan cara untuk menguasai bola dengan menggunakan kepala. Heading adalah teknik menanduk atau menyundul bola untuk mengoper atau mencetak gol, Luxbacher, J.A (2002). Bagian kepala yang digunakan untuk melakukan heading adalah kening. Namun terkadang ada pemain yang belum mahir melakukan heading menggunakan bagian atas kepala. Bagian ini sebenarnya cukup berbahaya, apalagi saat bola datang dengan laju yang cepat. Supaya aman, heading harus dilakukan dengan kening. Dan pada prosesnya tenaga dalam melakukan heading berasal dari otot leher.

Banyak pemain yang melakukan heading dengan menutup matanya. Padahal ini dapat mengakibatkan arah bola menjadi tidak menentu karena pemain tidak mengetahui ruang atau celah kosong di mana bola akan ditempatkan. Oleh sebab itu, pemain yang melakukan heading harus meyakini bahwa teknik yang satu ini bisa dilakukan tanpa harus menutup mata. Efek kesakitan yang dirasa pada bagian kening saat melakukan heading sebetulnya akan hilang dengan sendirinya. Bahkan dengan kombinasi heading menggunakan bagian samping pelipis mata, dapat membuat laju bola yang ditanduk menjadi susah ditebak.

Ishak. H. Pardosi (2008 : 78), “Cara menyundul bola yang baik adalah dengan menggunakan dahi dan mata harus tetap terbuka, jangan menggunakan ubunubun. Untuk melakukan sundulan yang keras, sebelum menyundul bola kepala dapat ditarik ke belakang. Teknik heading lainnya diberi nama the diving header, sundulan ini dilakukan dengan cara menjatuhkan badan ke depan dengan menggunakan dahi. Mengoper (passing) merupakan salah satu teknik dasar permainan futsal yang sangat dibutuhkan oleh setiap pemain, karena dengan lapangan yang rata dan ukuran lapangan yang kecil dibutuhkan passing yang keras dan akurat. Tipe passing berdasarkan jarak terbagi dalam 3 jenis, yaitu : Jarak pendek (short pass), jarak menengah (medium pass), dan jarak jauh (long pass).

Meningkatkan kemampuan teknik control, heading dan passing pada siswa ekstrakurikuler futsal SMP Negeri 13 Kota Bengkulu di harapkan siswa dapat memiliki kualitas teknik, skill yang baik dan menjadikan tim futsal SMP N 13 Kota Bengkulu dapat bersaing juara dengan SMP Negeri yang ada di Kota Bengkulu. Adanya pembinaan yang baik, kualitas tim yang sama rata menjadikan olahraga futsal di tingkat SMP Negeri Kota Bengkulu semakin banyak diminati dan berkembang.

Berdasarkan pendapat serta teoriteori yang dikemukakan para ahli seperti yang dipaparkan dalam kajian teori. Peneliti berpendapat bahwa dengan meningkatnya kemampuan teknik-teknik dalam olahraga futsal sangat mempengaruhi prestasi siswa SMP N 13 Kota Bengkulu, terutama dalam teknik heading, dengan melakukan teknik heading yang tepat, siswa dapat lebih memaksimalkan bola-bola yang ada diudara dalam mengumpan, mencetak gol, dan melakukan pertahanan.

Untuk dapat memenangkan permainan futsal, maka pemain harus memiliki kemampuan teknik yang baik dan kerjasama yang baik dalam permainan futsal. Teknik untuk mendorong kemampuan (skill) individu seorang, sedangkan kerjasama untuk menyatupadukan tim supaya bisa bermain 
dengan baik saat menyerang maupun bertahan. Penelitian ini membahas tentang analisis kemampuan teknik control, heading dan passing futsal, khususnya peserta ekstrakulikuler futsal SMP N 13 Kota Bengkulu yang berjumlah 30 siswa, dengan tiga variabel yaitu teknik control, heading dan passing pada olahraga futsal.

\section{Gambar 1 : Kerangka Berpikir}

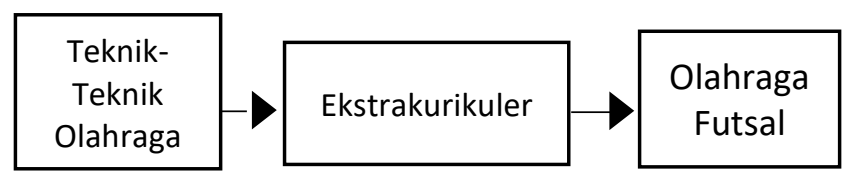

\section{METODE}

Penelitian ini merupakan penelitian deskriptif kuantitatif yang menggambarkan situasi atau keadaan yang sedang berlangsung dengan melakukan tes. Penelitian deskriptif kuantitatif merupakan salah satu jenis penelitian yang spesifikasinya adalah sistematis, terencana, dan terstruktur dengan jelas sejak awal hingga pembuatan desain penelitiannya. Desktiptif kuantitatif adalah penelitian dengan cara mengumpulkan data-data sesuai dengan yang sebenarnya kemudian data-data tersebut disusun, diolah dan dianalisis untuk dapat memberikan gambaran mengenai masalah yang ada. Berdasarkan penjelasan tersebut penelitian ini menggunakan metode teknik tes.

Pelaksaan tes control dan passing :

a. Sebelum pelaksaan tes dimulai para siswa diberi pengarahan mengenai analisis teknik dasar pada permainan futsal.

b. Siswa melakukan teknik dasar control dan passing dengan bola.
Pelaksanaan tes Heading :

a. Pelaksana tes berada di hadapan peserta tes yang tidak jauh dari sasaran jatuhnya bola yang akan disundul oleh peserta tes.

b. Peserta tes berada pada garis start dengan memegang sebuah bola.

c. Peserta tes melambungkan bola ke atas, melentingkan tubuh, pada saat bola menurun maka disambut dengan kepala peserta tes untuk melakukan sundulan sejauh mungkin.

d. Pelaksana tes menuju jatuhnya bola untuk memberikan tanda dan melakukan pengukuran langsung.

e. Sundulan ini dilakukan sebanyak 3 kali dan diambil pengukuran dari hasil tes pengukuran paling jauh.

\section{HASIL DAN PEMBAHASAN}

Hasil

Total keseluruhan aktivitas teknik control yang dilakukan siswa pada satu permainan sebanyak 2673 kali dengan uraian control benar sebanyak 2196 kali (82\%) dan control salah sebanyak 477 (15\%). Perolehan data heading didapat melalui tes yang dilakukan dengan cara menyundul bola sejauh mungkin menggunakan dahi kepala, kemudian dilakukan sebanyak 3 kali dan hasil yang di catat adalah hasil terjauh dalam melaksanakan tes menyundul bola sebanyak 3 kali. Berdasarkan sampel yang ditentukan dalam penelitian adalah total sampling maka hasil penelitian ini di deskripsikan yaitu 30 siswa ekstrakurikuler futsal SMP N 13 Kota Bengkulu. Total keseluruhan teknik passing yang dilakukan siswa pada satu permainan sebanyak 3099 kali dengan uraian passing benar sebanyak 2599 kali (84\%) dan passing salah sebanyak 500 kali (16\%). 
Dari data yang diperoleh dari tes kemampuan heading pada siswa ekstrakurikuler futsal SMP N 13 Kota Bengkulu, diperoleh hasil yang mendapatkan kategori baik sebanyak 8 siswa (27\%), kategori sedang sebanyak 16 siswa (53\%), kategori kurang sebanyak 6 siswa (20\%), sedangkan kategori baik sekali dan kategori kurang sekali tidak ada (0\%).

\section{Pembahasan}

Pembahasan ini akan membahas penguraian hasil penelitian tentang analisis teknik control, heading dan passing dalam permainan futsal. Permainan futsal merupakan salah satu cabang olahraga yang hamper mirip dengan permainan sepak bola, dengan ukuran lapangan, peraturan pertandingan, dan jumlah pemain yang tidak sama dengan permainan sepak bola. Permainan futsal dilakukan di lapangan yang lebih kecil dari lapangan sepak bola, dan jumlah pemain pada satu tim juga lebih sedikit dari tim sepak bola. Dengan jumlah pemain yang lebih sedikit, maka setiap pemain memiliki tugas dan peran yang sama yaitu harus mampu menyerang dan bertahan dengan baik, selain itu juga dengan ukuran lapangan yang lebih kecil maka sering terjadi benturan dan gesekan antar pemain dalam perebutan bola. Dengan kondisi permainan yang seperti itu, maka penguasaan teknik dasar yang baik dari setiap pemain mutlak sangat dibutuhkan, sehingga penguasaan bola dapat dikendalikan dan lebih dapat memaksimalkan bola dalam situasi-situasi apapun.

Berdasarkan analisis peneliti tentang kemampuan teknik control, heading dan passing siswa ekstrakurikuler futsal SMP Negeri 13 Kota Bengkulu yang dilakukan peneliti terhadap 30 sampel siswa ekstrakurikuler futsal SMP N 13 Kota Bengkulu didapat tingkat kemampuan teknik control benar dengan persentase sebesar $82 \%$, teknik heading dominan tergolong kategori sedang dengan persentase sebesar $53 \%$, teknik passing benar dengan persentase sebesar84\% dari seluruh siswa ekstrakurikuler futsal SMP N 13 Kota Bengkulu sebanyak 30 siswa. Menguasai teknik-teknik dalam permainan futsal sangat diperlukan dalam bermain futsal, salah satunya yaitu teknik heading, dengan melakukan heading dengan benar maka pemain lebih dapat memaksimalkan dan memenangkan bola-bola diudara baik dalam bertahan maupun menyerang atau mencetak gol.

Siswa ekstrakurikuler futsal SMP Negeri 13 Kota Bengkulu sudah cukup baik dalam melakukan teknik control dan passing dilihat dengan dominannya persentase yang diperoleh siswa dalam melakukan control dan passing, tetapi siswa ekstrakurikuler futsal SMP Negeri 13 Kota Bengkulu masih banyak yang belum dapat melakukan heading dengan benar, dilihat dengan diketahuinya hasil tes kemampuan heading pada siswa tidak ada siswa yang mampu memperoleh jarak lebih dari 10 meter atau yang termasuk kategori baik sekali. Pelatih mulai menerapkan latihan tambahan khusus pada jam ekstrakurikuler futsal SMP N 13 Kota Bengkulu dengan latihan meningkatkan kemampuan heading bagi siswa. Ketepatan dahi pada kepala dan ayunan otot leher pada siswa sangat mempengaruhi hasil kemampuan heading siswa. Ketika pemain futsal telah menguasai dengan baik teknik-teknik dalam bermain futsal, maka kombinasi antara pemain akan menghasilkan permainan yang bagus dan SMP N 13 Kota Bengkulu dapat menjuarai setiap kompetisi yang ada.

Tabel 1. Distribusi Frekuensi Tes Heading

\begin{tabular}{|c|c|c|c|c|}
\hline NO & Skor & \multicolumn{2}{|c|}{ Frekuensi } & \multirow{2}{*}{ Kriteria } \\
\cline { 3 - 4 } & & Absolut & Relative (\%) & \\
\hline 1 & $\geq 82$ & 0 & $0 \%$ & $\begin{array}{c}\text { Baik } \\
\text { Sekali }\end{array}$ \\
\hline 2 & $67-81$ & 8 & $27 \%$ & Baik \\
\hline 3 & $52-66$ & 16 & $53 \%$ & Sedang \\
\hline 4 & $37-51$ & 6 & $20 \%$ & Kurang \\
\hline 5 & $\leq 36$ & 0 & $0 \%$ & Kurang \\
\hline
\end{tabular}




\begin{tabular}{|c|c|c|}
\hline & & \\
\hline Jumlah & 30 & $100 \%$ \\
\hline $\begin{array}{l}\text { Rata-rata } \\
\text { Skor }\end{array}$ & 6,5 & \\
\hline $\begin{array}{l}\text { Skor } \\
\text { Tertinggi }\end{array}$ & $8,50 \mathrm{~m}$ & \\
\hline $\begin{array}{l}\text { Skor } \\
\text { Terendah }\end{array}$ & $4,30 \mathrm{~m}$ & \\
\hline
\end{tabular}

\section{PENUTUP}

\section{Simpulan}

Berdasarkan hasil penelitian yang telah diperoleh maka dapat di ambil kesimpulan sebagai berikut :

Total keseluruhan aktivitas teknik control yang dilakukan siswa pada satu permainan sebanyak 2673 kali dengan uraian control benar sebanyak 2196 kali (82\%) dan control salah sebanyak 477 kali (15\%), dengan rata-rata control yang dilakukan pada satu permainan sebanyak 891 kali dengan uraian control benar sebanyak 732 kali dan control salah sebanyak 297 kali.

Hasil tes keseluruhan heading dari 30 siswa yang mengikuti ekstrakurikuler futsal SMP N 13 Kota Bengkulu diperoleh hasil yang mendapatkan kategori baik sebanyak 8 siswa (27\%), kategori sedang sebanyak 16 siswa (53\%), kategori kurang sebanyak 6 siswa (20\%), sedangkan kategori baik sekali dan kategori kurang sekali tidak ada (0\%). Rata-rata hasil tes keseluruhan heading pada 30 siswa sebesar 6,5 dengan skor tertinggi 8,50 $\mathrm{m}$ dan skor terendah 4,30 $\mathrm{m}$. Dengan banyak nya siswa yang masuk dalam kategori sedang dan tidak adanya siswa yang masuk dalam kategori baik sekali, siswa diharapkan lebih mampu memaksimalkan kemampuan heading dengan penambahan waktu dalam program latihan tambahan pada ekstrakurikuler futsal SMP N 13 Kota Bengkulu. Total keseluruhan aktivitas teknik passing yang dilakukan siswa pada satu permainan sebanyak 3099 kali dengan uraian passing benar sebanyak 2599 kali (84\%) dan passing salah sebanyak 500 kali (16\%), dengan rata-rata passing yang dilakukan pada satu permainan sebanyak 1033 kali dengan uraian passing benar sebanyak 866,3 kali dan passing salah sebanyak 166,7 kali.

Dengan siswa berlatih sungguhsungguh dan rutin diharapkan kemampuan control, heading dan passing siswa menjadi lebih baik agar siswa lebih mampu memaksimalkan bola baik dalam bertahan maupun menyerang dan mencetak gol dalam permainan futsal.

\section{Saran}

Ada beberapa saran yang perlu disampaikan sehubungan dengan hasil penelitian ini, antara lain :

1. Sesuai dengan hasil penelitian diketahui teknik dasar control mempunyai tingkat keberhasilan yang paling rendah, hal ini dapat dijadikan bahan kajian bagi para pelatih untuk meningkatkan kemampuan teknik dasar control.

2. Sesuai dengan hasil penelitian diketahui bahwa teknik heading mempunyai tingkat keberhasilan yang termasuk rendah, heading merupakan hal yang cukup sederhana dilakukan, tetapi apabila lebih di maksimalkan dalam latihan maka hasil dan manfaat yang di peroleh akan sangat baik.

3. Dengan banyak siswa yang masuk dalam kategori sedang, hal ini dapat dijadikan bahan kajian bagi para pelatih untuk meningkatkan dan lebih memaksimalkan kemampuan teknik heading siswa esktrakurikuler futsal SMP N 13 Kota Bengkulu.

4. Hasil penelitian menunjukan bahwa teknik dasar passing mempunyai 
tingkat keberhasilan yang tinggi, hal ini dapat dijadikan bahan kajian bagi para pelatih untuk mempertahankan kemampuan teknik dasar passing pemain.

5. Penelitian ini juga bertujuan sebagai referensi pelatih, dimana pelatih bisa mengetahui dimana letak kekurangan tim futsal SMP N 13 Kota Bengkulu sehingga bisa memperbaiki keadaan tim futsal tersebut agar menjuarai setiap kompetisi. Hasil penelitian ini juga digunakan sebagai bahan evaluasi bagi pelatih untuk mengetahui kemampuan pemainnya.

\section{DAFTAR PUSTAKA}

Arikunto, Suharsini. 2006. Prosedur Penelitian Suatu Pendekatan Praktik. Jakarta: PT Rineka Cipta.

Arsil. (2009). Evaluasi Pendidikan Jasmani dan Olahraga. Malang : Wineka Media.

Ekkry, Yarmani, Santun, dan Defliyanto. 2018. "Pengaruh Metode Latihan Teknik Distribusi Terhadap Keterampilan Dribbling Zig - Zag Permainan Futsal". Jurnal Kinestetik, Vol. 2 (2).

Irawan, Andri. 2009. Teknik Dasar Modern Futsal. Jakarta: PT Pena Pundi Aksara.

Ishak H. Pardosi dan Justinus Lhaksana. (2008). Inspirasi dan Spirit Futsal. Jakarta: Raih Asa Sukses.

Justinus Lhaksana (Ex-Pelatih kepala Timnas Futsal Indonesia) (2011). Taktik dan Strategi Futsal. Depok: Be Champion (Penebar Swadaya Group).

Muhammad Asriady Mulyono. (2014). Buku Pintar Panduan Futsal. Jakarta: Laskar Aksara
Murhananto. (2006). Dasar-Dasar Permainan Futsal. Jakarta: PT Kawan Pustaka.

R. Aulia Narti. (2007). FUTSAL. PT Indahjaya Adipratama.

Sugiyanto , Bogy, dan Defliyanto. 2019. "Implementasi Metode Rondo Untuk Meningkatkan Teknik Passing Mahasiswa Pada Mata Kuliah Futsal Penjas Prodi Penjas FKIP UNIB". Jurnal Kinestetik, Vol. 3 (1).

Tangkudung, James. (2012). Kepelatihan Olahraga Pembinaan Prestasi Olahraga. Jakarta: Cerdas jaya . ,(2016).Macam-macam

Metodologi Penelitian. Jakarta: Lensa Media Pustaka Indonesia. ,(2018). Sport Psychometrics

Dasar-dasar dan instrument Psikometri. Depok :Rajagrafindo persada.

Widyastuti. (2011). Tes dan Pengukuran Olahraga. Jakarta : PT. Bumi Timur Jaya. 